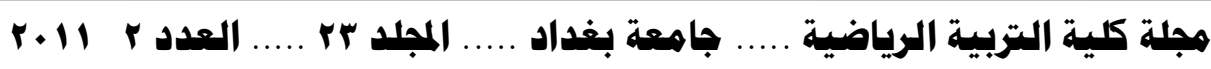

نموذج هقتزح لتتوظيف الماسوب الإلكتزوني في دروس

التزبية الرباضية للدارس تربية الكرخ / الإتوسطة

\author{
م. م. عبد السملام همهمد حسين \\ كلية التزبية الرباضية - جاوهمة بهداد
}

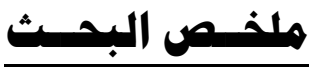

هدفت هذه الدراسة إلى إعادة صياغة مفهوم المنهج التكنولوجي في ظل مدارس تربية الكرخ الاولى المتوسطة، ويناء نموذج عملي لتوظيف منظومات التعليم بالحاسوب الإكتروني لتحديا بنية داعمة لمنهاج الموجه لدروس التربية الرياضية وتقديم مجموعة مسن التوصسيات للدعم توظيـف منظومـات التعليم بالحاسـوب الإكترونـي في المــارس ، ولتحقيق أهداف الدراسة فقد سعت إلى الإجابة عن الأسئلة :ما مفهوم المنهج التكنولوجي الحديث في ظل المـارس المتوسطةٌ ومـا النمـوذج العملـي المناسب لتوظيف منظومـات التعليم بالحاسـوب الإكترونـي في ضوء تكنولوجيا التعليم؟ ومـا البنيـة الداعمـة للمنهـاج الموجه نحو الاقتصاد المعرفي في ضوء حوسبة المنـاهج؟ وما التوصيات المقترحة لدعم توظيف منظومـات التعليم بالحاسـوب الإكترونسي في المدارس المتوسطة؟ وقد استخدمت الاراسة منهج البحث الوصفي التحليلي وتوصلت إلى مجموعة من النتائج ، أهمها نموذج مقترح لتفعيل استخدام منظومات التعليم الإلكتروني في المدارس المتوسطة لاروس التربية

الرياضية في تريبة الكرخ الاولى وامكانية تعميها على باقي المدارس في القطر العراقي . 


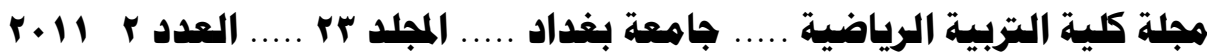

\section{The Abstract}

This study aimed at reconstructing the Technology Approach with respect to psychology families, proposing a practical model to implement education and e-learning systems, defining the needs of planning curricula based on knowledge economy use, and recommendations of how to utilize elearning systems in schools. The study tried to answer four questions:1)What is the new concept of technology approach in designing curriculum?, 2) what is the practical model needed to implement computerized education system according to educational technology?, 3) what are the needs of planning curricula based on knowledge economy use?, 4) What are the recommendations of utilizing e-learning systems in schools?.

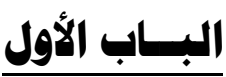

\section{1 - التعريف بالبحث ا ا-1 المقدهة وأهمية البحث}

جهدت ا مديرية النشاط الرياضي والكثفي في مديرية تربية الكرخ / ا في محاولات مواكبة تحديات العولمـة والتطور التكنولوجي الذي طال جميع منـاحي الحياة ، مما تطلب إخضـاع ميدان التربيـة الرياضـية لضـرورة مسـايرة هـا التطور ، لئلا تـزداد الفجـوة بـين المدرسة والحياة والتعلم التعلم الحركي، وقد حاولت بعض المدارس ذات المستوى المتقدم ، الاستفادة من تكنولوجيا المعلومـات والاتصـالات ، ودمجها في النظام التربـوي بعيدأ عن إطار تكنولوجيا التعليم التي تستخدم هذه التكنولوجيا كواحدة من أدواتها في تحقيق تعلم فعال متوجه نحو الاقتصاد المعرفي، أو المدخل التكنولوجي للمنهج الذي فرض نفسه في ظل هذا التغير المتسارع التقدم العلمي الحاصل في الدول المتقدمة وخصوصـا في الميدان التريوي ويالذات في مناهج التربية الرياضية التي استخدت واختزلت الكثير من النظريات القديمة في التعل الحركية باستخدمها التقتية الحديثة والاستفادة من خصائص الحاسوب 


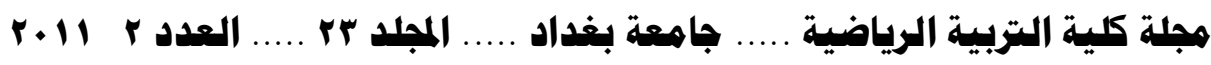

الاليكتروني في تسريع عملية التعلم واتقانها خصوصا في مفردات دروس التربية الرياضية

لقد أدى التطور في مجـال تكنولوجيـا المعلومسات والاتصـالات إلـى فرض أسس جديدة

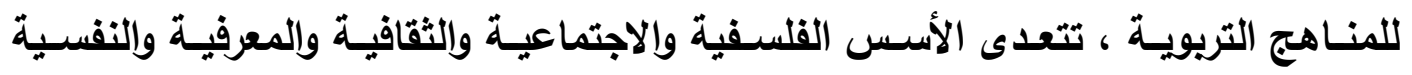

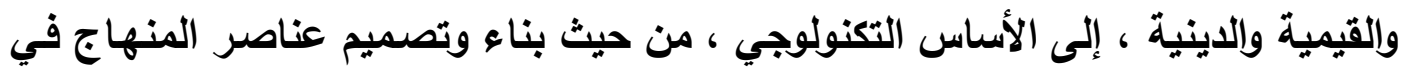

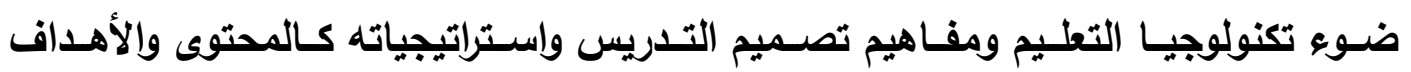

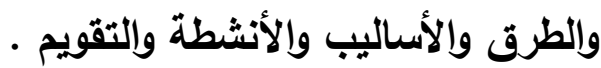

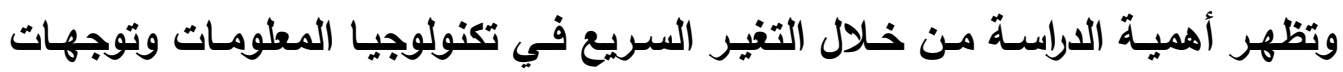

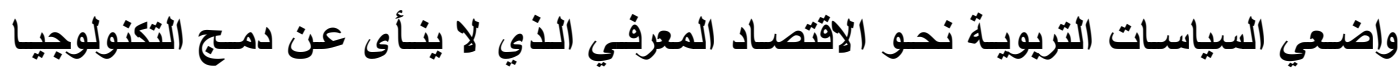

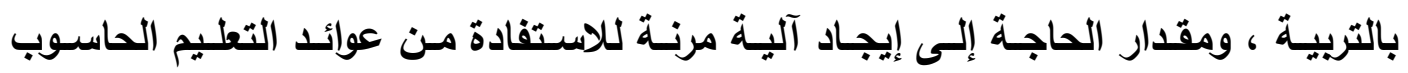

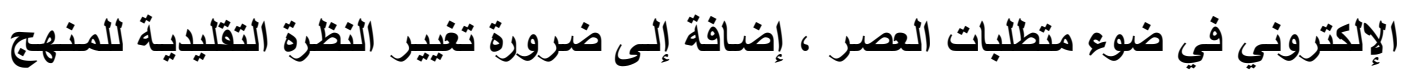
التكنولوجي بارتباطه بالمدرسة التريوية.

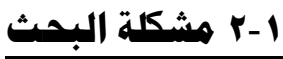

تتحدد مشكلة البحث في الآتي: 1. ضعف البنية التحتية في المدارس لتوظيف منظومات التعليم بالحاسوب الإكترونسي نحو تعلم المهارات الرياضية في كرة السلة والجمناستكل. r. ضعف تدريب الكوادر التعليمية الموجه نحو تكنولوجيا التعليم.

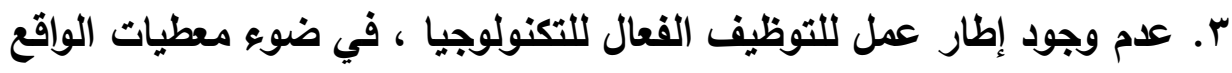
؛. ضعف تصميم المنهاج الموجه نحو الاقتصاد المعرفي في ضوء أهداف هذه البحث، يمكن تحديد الأسئلة التي نحاول الإجابة عنها بما يأتي:

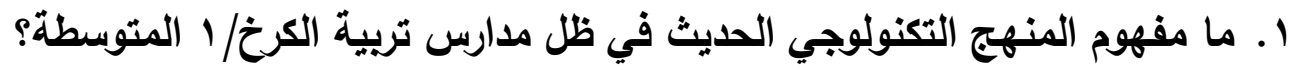




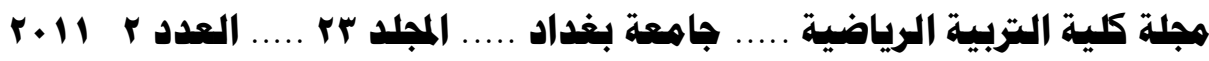

r. ما النموذج العملي المناسب لتوظيف منظومـات التعليم بالحاسوب الإكترونـي في ضوء تكنولوجيا التعليم؟

r. مـا البنيـة الداعمـة للمنهـاج الموجـه نحو الاقتصـاد المعرفي في ضـوء حوسبة

المناهج?

ع. مـا التوصيات المقترحة لدعم توظيف منظومـات التعليم الإكترونـي في المدارس

المتوسطة؟

r- r r أهداف البمث

يهرف البحث إلى:

ا ـ إعادة صياغة مفهوم المنهج التكنولوجي

r . بناء نموذج عملي لتوظيف منظومات التعليم التعليم الإكتروني.

r. التعرف على فاعلية توظيف التعلم بالحاسوب الاليكتروني في تعلم بعض مهارات

الجمناستك

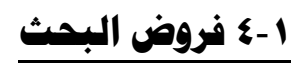

ا ـ توجد فروق معنويـة بـين الاختبـارات القبليـة والبعديـة في مسـتوى تعلـم مهـارة

الوقوف على الراس لمجوعتي البحث

r. توجد فورق معنوية بين الاختبارات البعدية لمجموعتي البحث

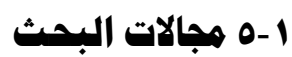

1-ه-1 المجال البشري: طلاب متوسطتي المأمون وعمار بن ياسر في تربية الكرخ / 1

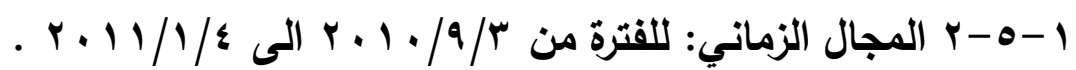

1-0-r المجال المكاني: الساحات والقاعات الاخلية للمدارس المشمولة بالبحث

وهي(متوسطة المامون ومتوسطة عمار بن ياسر) للبنين - تربية بغداد الكرخ / 


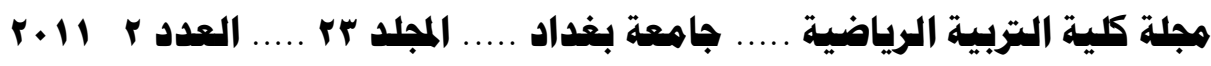

\section{البــاب الثانــي}

\section{r r الدراسات النظرية \\ r- هفهوم المذهج التكنولوجي}

يعرف المنهج التكنولوجي على أنه مجموعة المواقف التعليمية التعلمية التي يستعان

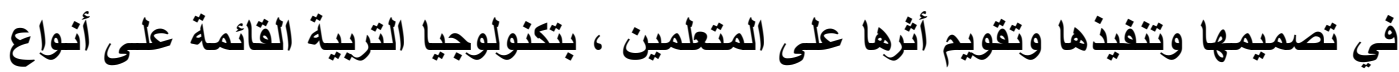
التعلم الأتي من أجل تحقيق أهداف محددة يمكن تحقيقها وقياسها. ( ' ).

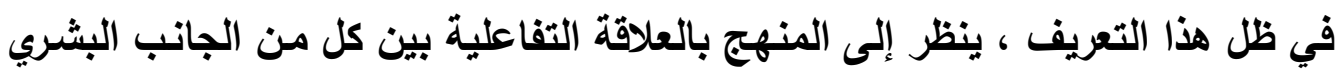

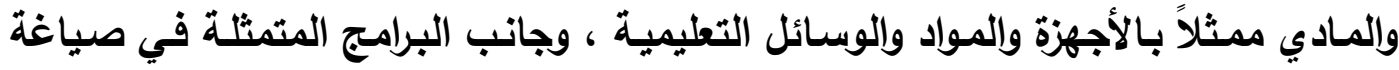
المحتوى المعروض ، وجانب تصميم هذا الموقف التفاعلي.

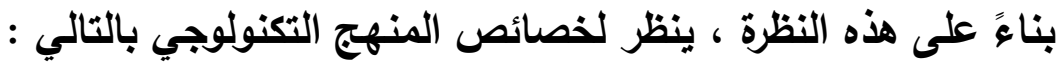

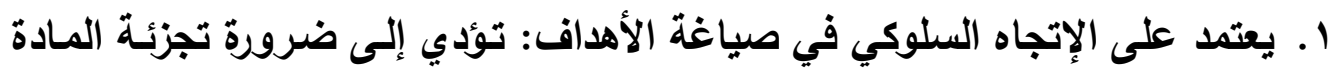
العلمية إلى أبسط عناصرها. r. الاعتماد على المشـاركة الإيجابية للمتعلم ليتقلم بشكل تلقائي بصرف النظر عن

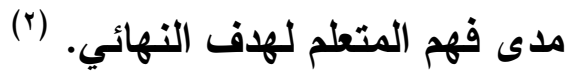
لذا فإن تقديم البرنـامج التعليمي يتم بصورة اسـهل بـاء على منهجج المسادة الدراسية ويتطلب ذلك اختيار الوسـائل التعليميسة المسـاعدة وسـهولة تقديمها لاكتسـاب المعلومـات الخاصة بالمهارة وادراك معنى واهميتة المطلومات المرتبطة بتعلم المهارة وإكتساب الخبرة.

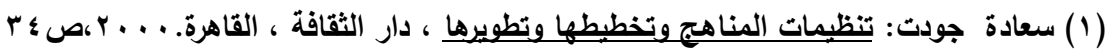

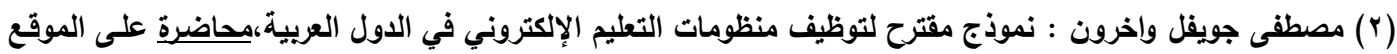
الاليكتروني www.almdares.net. تكنولوجيا التعلم. 


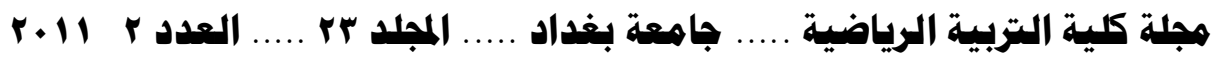

r r r التعليم بالحاسوب الالكيتزوني وتكنولإوجيا المعلوهات

إن الفصل بين مفهومي التعليم الإلكترونسي وتكنولوجيا المعلومـات والاتصسال عن

تكنولوجيا التعليم ، ينزع النظرة الشمولية التي تأخذ بها تكنولوجيا التعليم لعناصر المنهاج التي يمكن التعامل معها في المنحى النظامي كاساس لمفهوم تصميم التدريس ، فلا ينظر إلى استخدام التكنولوجيا في مجال التربية على أنه مجرد الاستعانة ببعض أنواع التقتيات في التدريس ، بل هي تحليل للمشكلات التعليمية والتفكير في إيجاد حلول مبتكرة لها. عمـدت بعضض وزارات التربيـة والتعلـيم فـي الــدول العربيـة مـن مثـل (الأردن و السعودية) ، على تطبيق منظومات التعليم الإلكتروني في مدارسها ، إلا أن المسئولين عن رسم السياسـة التريويـة والتخطيط للمنـاهج قد واجهوا تحديات ومعوقات كثيرة تقف أمسام تطبيتق منظومـات التعليم الإلكترونسي ، سـواءً كانت هذه المعوقات واضحة للعيان أو في خفاء لا يشعر بها إلا من كان في الميدان من معلمين وإداريين ، والأهم ، العائد التعليمي على الطالب نفسـه ، والذي لا يتضمن المعرفة فحسب وإنمـا يتعد ذلك إلى تثـيل بنى معرفية لاى المتعلم تتعلق باستراتيجات التعلم في كل ميدان من ميادين المعرفة ، وقدرة المعلم على تطوير استراتيجيات تلريسية تتناسب في واستراتيجات التعلم لاى الطلبة مـع القدرة على الوصـول إلى تلك الاسـتراتيجيات في مراحل تصـيم وتتفيذ وتقويم الموقف التدريسي.

لقد غيب المتخصصون في تكنولوجيا التعليم عن رسم سياسات التعليم الإكتروني ، ويتضـح ذلك مـن خـلال المفـاهيم المغلوطـة عن تكنولوجيا التعليم والخلط بينها ويسين تكنولوجيا المعلومات والاتصالات التي تعتبر من أدواتها ، إضـافة إلى فصل مفهوم التعليم الإلكتروني عن مفهوم تكنولوجيا التعليم مع أنه واحد من تطبيقات المنحى التكنولوجي في المنـاهج ، كمـا غيب مفهـوم نمـاذج التعليم المنبثقة مسن العـائلات الرئيسـة لعــم الـنفس (السلوكية والمعرفية والإنسانية والاجتماعيةة) ونظريـات التعلم المنبثقة منها ، مـع تغييب 


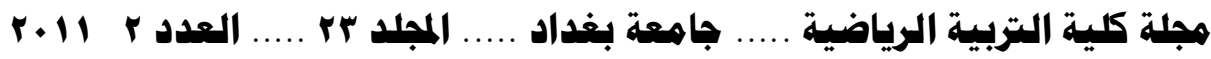

مفهوم تصميم التدريس واعتمـاد مفهوم النشاط كتطبيق لفلسفة ديوي في أن التعليم هو الحياة ، كما يـلاحظ من تصميم المنـاهج وأطرها العامـة وترجمـة ذلك إلى الكتب المدرسية التي ابتعد في تأليفها عن التوجه نحو الاقتصاد المعرفي الذي يعنى بتوظيف المعرفة في توليد معرفة جديدة يمكن أن تساهم في الناتج القومي كمنعس لنتاجات تعلم الطلبة.(1)

\section{البـباب الثالهـث}

r- هنهمية البحث واجراته الميدانية

r- م- هنهج البحث المستخدم

للإجابة عن أسئلة الدراسـة ، ولتحقيق أهدافها ، استخدم الباحث المنهج الوصفي

التحليلي الأي يتفق مع طبيعة الدراسة.

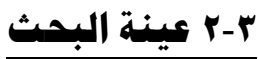

اختار الباحث عينة بحثة من طلاب المرحلة الثانية من متوسطتي المامون وعمار

بـن ياسـر التـابعتين لتربيـة الكرخ / / بــنغ عددهم ( • عطالبـا) لكـلا المجمـوعتين قسموا بالطريقة العشوائية الى مجموعتين بلغ عدد كل مجموعة ( • ب) طالبا. خضعت المجموعة الاولى السى تطبيق منطومسة التعلم بالحاسـوب الاليكتروني لفعاليـات الوقوف على الـراس بالجمناستك. وتركت المجموعة الثانية للتعلم المعتاد. r-r ادوات ووسائل جع المعلومهات

تـم بنـاء قاعـدة بيانـات (Meta-Data) تحتـوي على قطـع تعليميـة إلكترونيـة تحتوي على هدف تعليمي واحد ، وذلك يتطلب تجزئسة أهداف (E-Learning Objects) المباحث الدراسية إلى أهداف صغيرة مفردة يتم ريطها شبكياً وهرمياً ، ومرمزة بحيث تسهل على الطالب والمعلم الوصول إليها وتوظيفها في المواقف التعليمية التعلمية وفق المهارة

(1) Jwaifell, Mustafa. (2007). "E-Learning Objects Me style Enabled Educational class, Enhancing Blended learning" LINC Conference, Amman, Dubai 


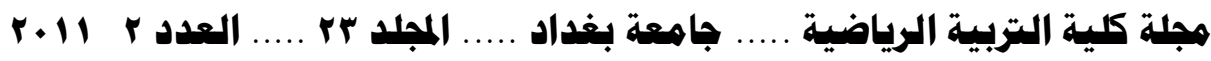

المـراد تعليمهـا ويسـهل تحميلهـا على منظومـة التعليم بالحاسـوب الإلكترونـي. وتـم عقد ورشات تدريبية لتصميم التدريس القائم على منحى التدريس المولف ، والابتعاد عن رسم خطط بعيدة المدى والتجريب العملي على بعض المدارس وإنمـا رسم خطة شـاملة يمكن تنفيذها بأقل وقت ممكن ، وقد امتـاز التعليم بالحاسـوب بــهـلة الـخول إلـى قواعد

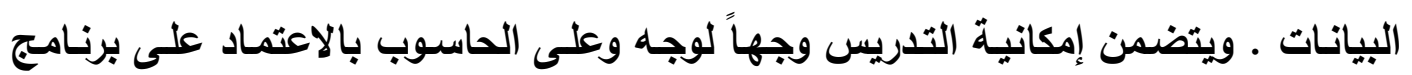
الكتروني خاص ومحتوى المادة المراد تدريسها ، ويمكن أن يتم ذلك بتوظيف حاسوب واحد في الغرفة الصفية ، أو بداخل مختبر الحاسوب . تعتمد مفردات النموذج على أساس بناء قاعدة بيانـات لقطع تعليمية إلكترونية يمكن أن يتم تحميلها على منظومة التعليم الإلكتروني ، أو في حال عدم توفر المختبرات التلازمـة ، فيمكن تحميلها على شبكة الحاسوب الداخلية للمدارس. فضلا عن ذلك استخدم الباحث الادوات الاتية:

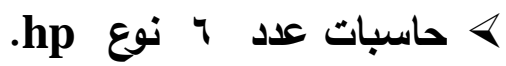

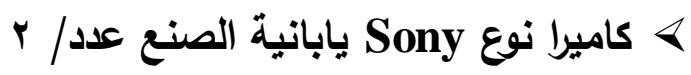

$$
\begin{aligned}
& \text { ه الصور } \\
& \text { ها اقراص ليزرية. } \\
& \text { هاشات شرض }
\end{aligned}
$$

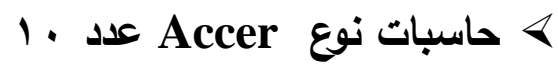

\&ultimedia Builder Ver 4.9.8.13 برنامج

Media Studio Pro Ver 8 برنامج Adobe Photoshop CS3 برنامج

Cool Record Edit Deluxe برنامج برسج \&ilisoft Avi Mpeg Converter برنامج 


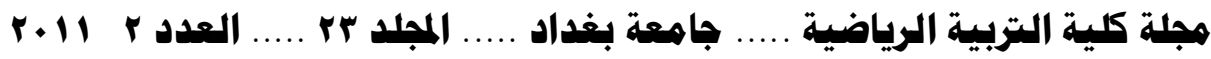

\section{Microsoft Paint برنامج

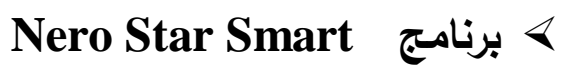

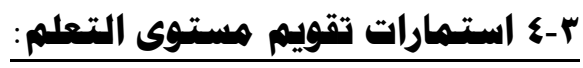

لجـا الباحث الى اعداد استمارات خاصسة لتقويم مسـتوى التعلم المهاري لمهـارة الجمناستك وتم عرضها على الخبراء المختصين بمادة التعلم الحركي والجمناستثك ، وتم الاخذ بهذه الاستمارات بعد الاتفاق عليها وتضمنت هذه الاستمارات ماياتي:

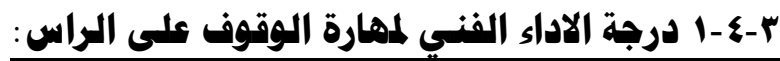

اعد الباحث الاستمارة وفقا لما جاء في الاراسـات الاجنبية المتخصصة في مجال التعلم والتعلم الحركي اذ اشسارت هذه الدراسـات على تقسيم درجـة الاداء وفقـا لمسـاهمة اجزاء الجسم في المهارات (1) من خلال اعداد استمارة تقويم خاصـة بذلك ،و تضمنت هذه الاستمارة درجة الاداء من خلال(حركة الذراعين - حركة الرجلين - حركة الجذع - حركة الرأس- ومجمل الحركة كاملة) r-ه قيساس هستوى التعلم والاحتفاظ

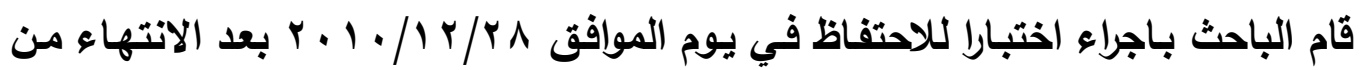
الاختبارات البعدية ويفاصل زمني (r Y ) يوماً للوقوف على النتائج الحقيقية لمقدار التعلم الحقيقي المحتفظ في ذاكرة الاداء بعد زوال المتغيرات الوقتية لاداء المتعلمين كافة، وتم تهيئة الظروف انفسها في الاختبارات القبلية والبعدية وللمهارات نفسها قيد البحث. لجأ الباحث الى استخدام القانون التالي وفقا للفترة الزمنية التي يستغرقها الفرد للتعلم ، وفيه يطلب من الفرد بعد ان يتعلم المهارة،ويعد فترة من الزمن(بعد الاختبار البعدي) يطلب منهـ ان اداء المهارة التي سبق ان تعلمها، وفي هذه الطريقة تحدد عدد التكررات التي تؤدي الى الوصول الى المستوى الفني المطلوب لاداء المهارة ، وعليه فان الاختبار بعد

(1) التحليل النوعي في علم الحركة، (ترجمة صريح عبد الكريم ووهبي علوان) الدار الوطنية للكتب والوثائق بغداد ـ . . . ،

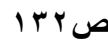
$=(r \cdot r)$ 


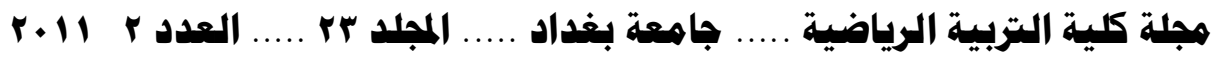

مدة الاحتفاظ سيكون اقل من اخر اختبار في المدة التعليمية ، ويقاس بخساب الفرق في الزمن او الجها الأي يحتاج اليه لاستعادة ماسبق تعلمه مطروحاً منه الزمن الذي استغرقه التعلم الاصلي، لاحظ المعادلة التالية:( )

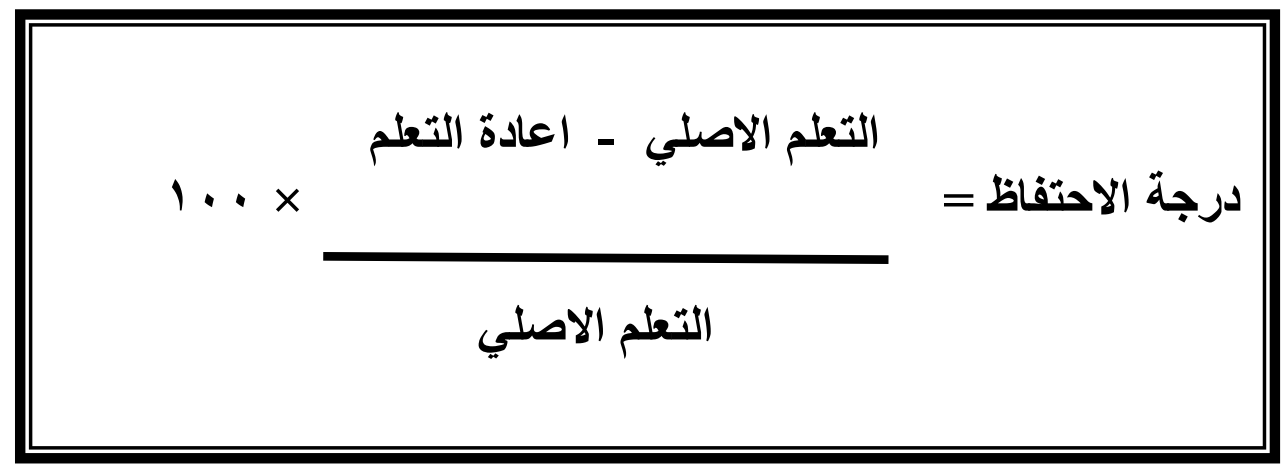

r-1 الاختبارات القبليية

حرص الباحث ان يكون افراد عينة البحث لايهم معلومات اولية عن المهارات قيد البحث قبل البـد بـاجراء الاختبـارات القبليـة ، لذا فقد اكد على ان جميع افراد العينة قد تعرضـوا لعمليـة تعليم هذه المهـارات خـلال الدروس العمليـة ومـن قبـل القـائمين بالعمليـة التعليمية ووفقا للمنهج الخاص بالتربية الرياضية لوزارة التربية-المديريـة العامـة للتربية الرياضسية، ووفقـا للظروف المتاحـة لهـم لتعلم هذه المهـارات، وقـ قـام الباحث بـاجراء

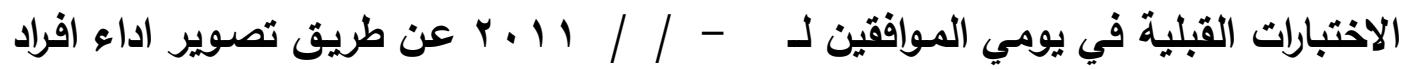
المجموعتين التجريبيتين وكلا حسب مهارته ويمساعدة فريق العمل المساعد. ووفق الاتي: ه تثبيت الكاميرات في موقعها لكل مهارة من المهارات قيد البحث ه ترتيب الطلاب وفق تسلسهم بقائمة تقييم الاداء. ه تصوير الاداء لكل فرد من افراد المجموعتين وحس المهارة.

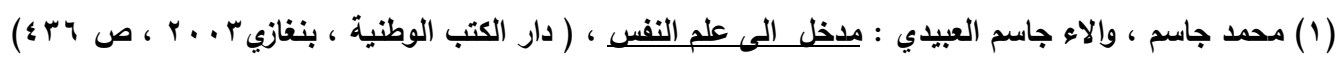
$(r \cdot r)$ 


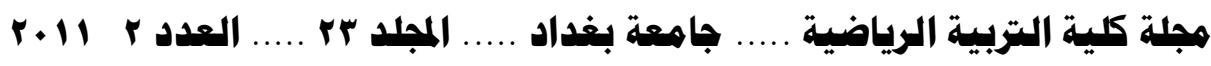

ه جمع الافلام المصورة وخزنها على اقراص ليزرية لغرض عرض هذه المهارات على الخبراء لتقبيمها كلاً حسب تخصصه.

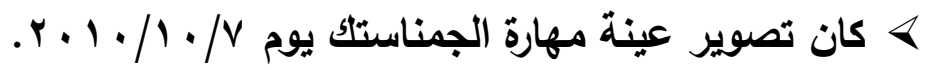

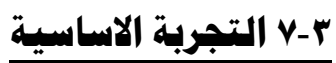

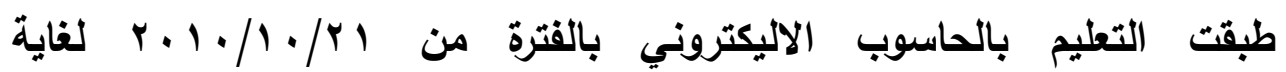

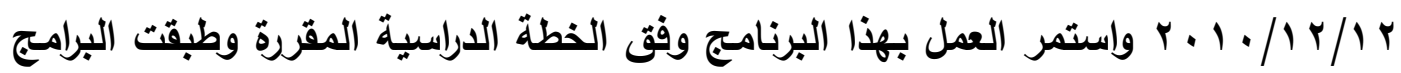
لمدة ثمانية اسابيع بواقع ساعتان بالاسبوع ( ساعات دراسية لكل تلميذ على شكل مجاميع لاتزيد كل عن ع -ه تلميذ). لذا كان عدد الوحدات التعليمية (7 ا ) وحدة تعليمية. كانت الوحدات التعليميـة تهتم بتعليم المهـارتين والـربط فيمـا بينهـا فيمـا يخص بعض الاقسام الحركية خصوصا الوضع التحضيري. تم تشغيل الحاسبات مسبقا وتثغيل البرامج التعليمية كلا حسب مهارته.

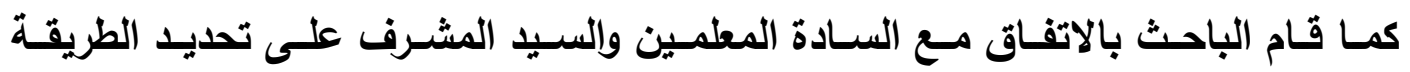
التدريسية A-r الاختبارات البعدية A

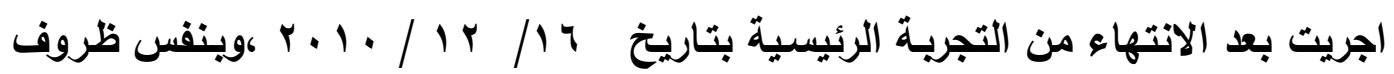
الاختبارات القبلية r-9 الوسائل الاهصائية أســتخدم الباحـث الوسـائل الاحصـائية(الحقيبة الاحصـائية للـرزم الاجتماعيـة) لمعالجة نتائج البحث وتحليلها ومناقثتها. 


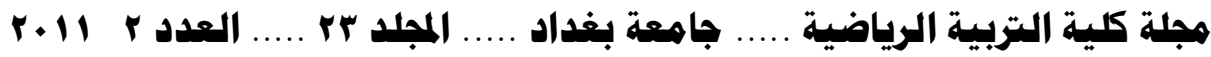

البــاب الرابـع

ع- عرض النتائج وهناقشتها:

ع-1 عرض نتائج همارة الوقوف على الراس قبلي - بعدي للمجومتين

(1) الجدول (1)

فرق الأوساط الحسابية والانحراف المعياري وقيمة (t) المحسوية ودلالة الفروق بين نتائج الاختبارين القبلي والبعدي في مستويات التعلم للوقوف على الراس للمجموعة

التجريبية

\begin{tabular}{|c|c|c|c|c|c|c|}
\hline الفروق & مستوى & المحسوية & ع هـ & فَتَ & وحدة القياس & المتغيرات \\
\hline معنوي & ., & $0, Y Y \wedge$ & ש & r,Y Y & درجة & الذراعان \\
\hline معنوي &,$\ldots$ & $0, O \wedge r$ & $\cdot, T r V$ & $r, 0 \ldots$ & درجة & الرجلان \\
\hline معنوي &., .10 & $r, r, l$ & I, rrr & צr, & درجة & الجذّع \\
\hline معنوي & $\cdot, \ldots$ & $\wedge, q \cdot \wedge$ & $\cdot, r \wedge r$ & $r, 01 \mathrm{~V}$ & درجة & الرأس \\
\hline معنوي & $\cdot, \cdot \varepsilon$. & $\wedge, \wedge \vee$. & $\cdot, \leqslant \vee q$ & $\varepsilon, Y_{0}$ & درجة & الحركة كاملة تقويم \\
\hline
\end{tabular}

$$
\begin{aligned}
& \text { * درجة الحرية (· ( } 19=1 \text { ( ). } \\
& \text { * معنوي عند مستوى الخطأ } \geq \text { (0., . . }
\end{aligned}
$$

يلحظ من الجدول السـابق ان قيم متوسط الفروق للرجات مستوى التعلم للوقوف على

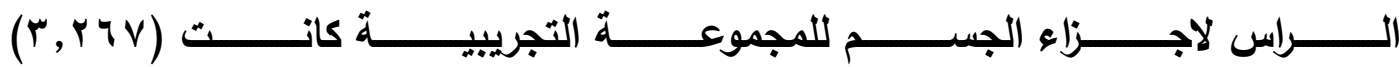

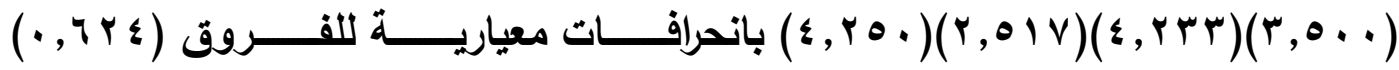

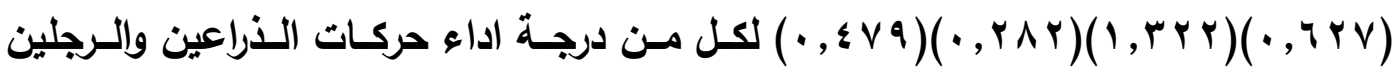

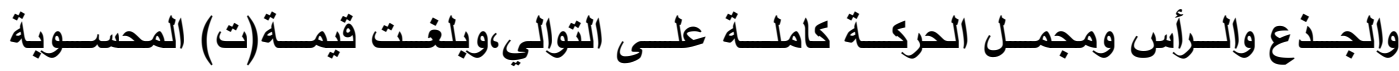

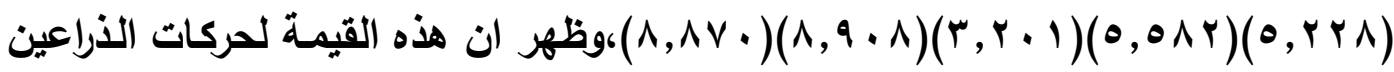




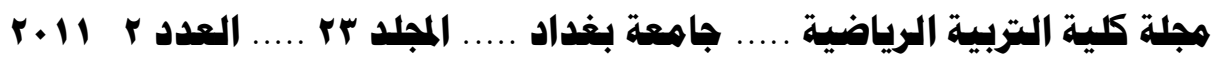

والر جلين والرأس والجذع فضلا عن درجة تقويم الحركة كاملة معنويـة عند مستوى دلالة

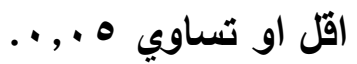

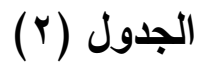

فرق الأوساط الحسابية والانحراف المعياري وقيمة (t) المحسوية ودلالة الفروق بين نتائج الاختبارين القبلي والبعدي لارجات مستوى التعلم للوقوف على الراس قيد البحث

للمجموعة الضابطة

\begin{tabular}{|c|c|c|c|c|c|c|}
\hline الفروق دلاكة & مستوى & قيمة & ع هـ & فَتَ & وحدة القياس & لمتغيرات \\
\hline عشوائي & r., & $r, \varepsilon \varepsilon r$ & $\cdot, r r r$ & $\cdot, 0 \leq \mu$ & درجة & الأراعان \\
\hline معنوي & $\cdot, r \varepsilon$ & r r & • & ., $99 \leq$ & درجة & الرجلين \\
\hline عشوائي &., 00 & $r, 0 \leq$. & $\cdot, r \cdot V$ & .,OrV & درجة & الجذع \\
\hline عشوائي &., .70 & $r, r, I$ & $\cdot, \varepsilon \cdot r$ & $\cdot, \wedge \wedge \neg$ & درجة & الرأس \\
\hline عشوائي & $\cdot, \wedge 1$ & $r, V \backslash r$ & $\cdot, 9 \leq 1$ & Y.00 & درجة & الارجة \\
\hline
\end{tabular}

$$
\begin{aligned}
& \text { * درجة الحرية (• ( } 19=1 \text { ) ). }
\end{aligned}
$$

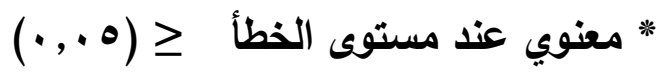

يلحظ من الجدول السـابق ان قيم متوسط الفروق للرجات مستوى التعلم للوقوف على

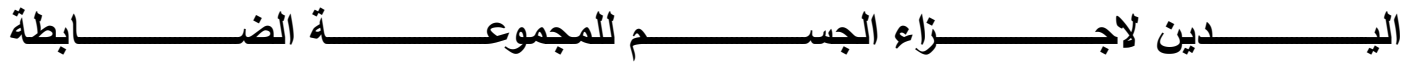
كانــــــــ

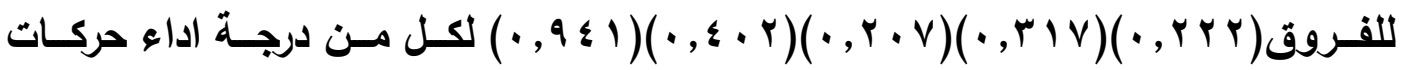

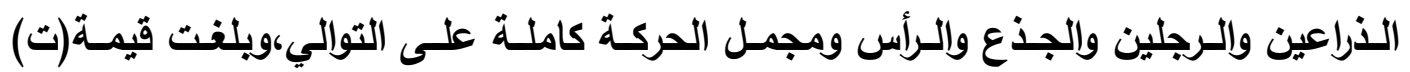

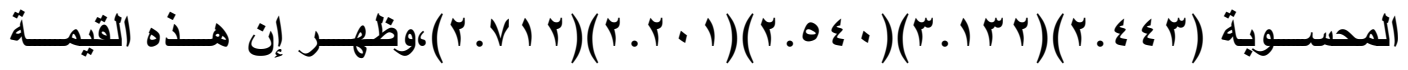




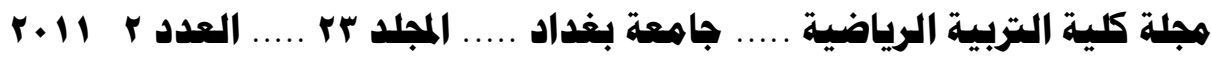

بالنسبة لحركات الذراعين والرأس والجذع والحركة الكلية غير معنوية عند مستوى دلالـة

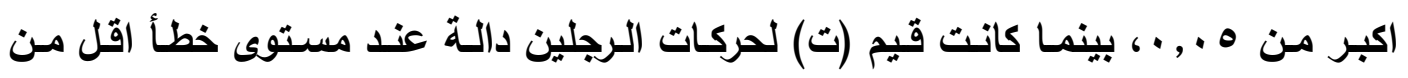
$\cdot, \cdot 0$

ان ظهـور الفـروق المعنويـة في مستوى اداء حركـات اجزاء الجسـم كـان بسـبب ان

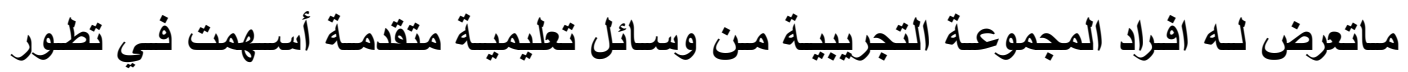

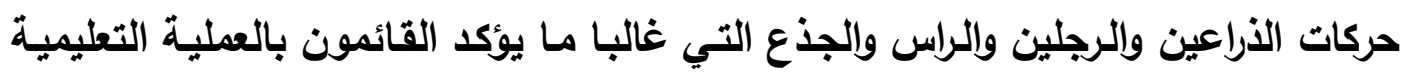

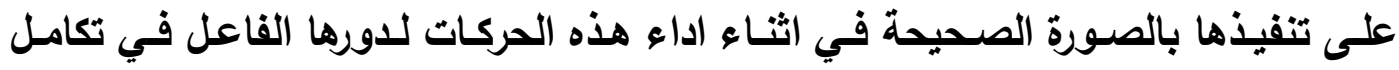

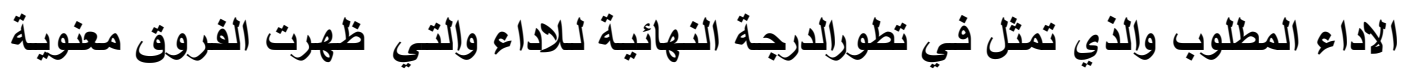

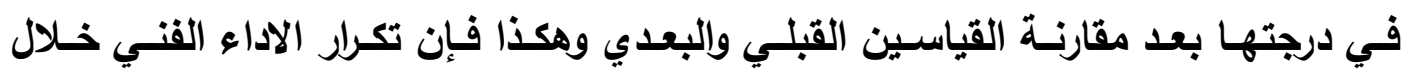
الدروس العملية لهذه المهارات من خلال استخدام الحاسوب يعطي مردودات ايجابية في

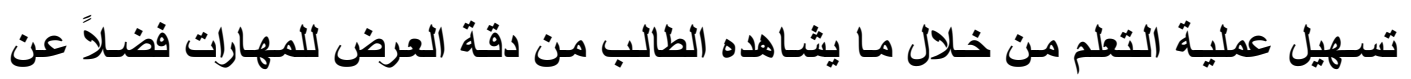

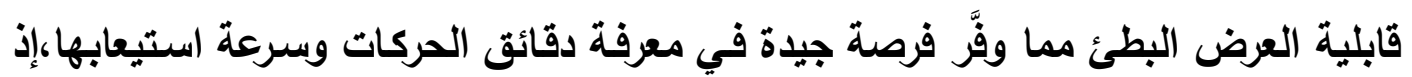

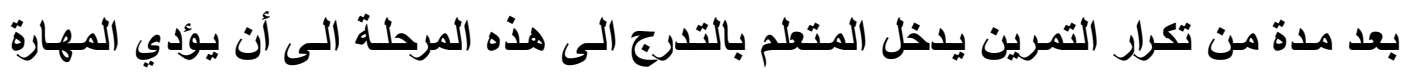

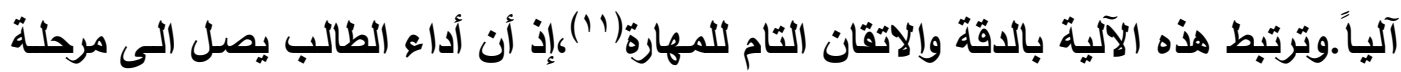

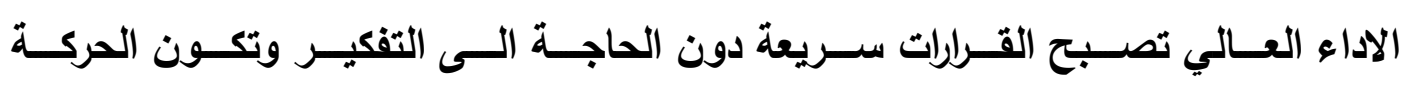
انسيابية(الأنموذج الحركي العالي المستوى)

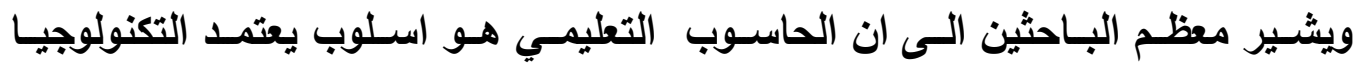

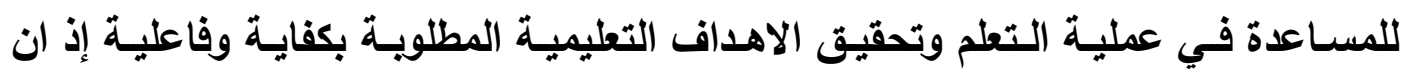
استخدام الحاسوب ويرامجها كمنظومـة متعددة الوسـائل ويشكل وحدة نظامية مقتنـة تعمل الاهل

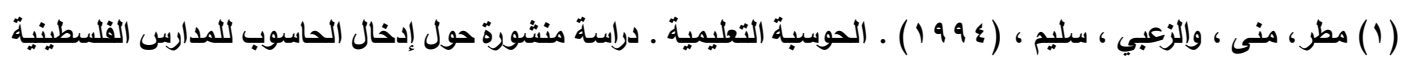

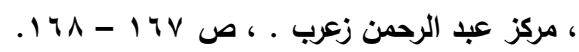
$(r \cdot v)$ 


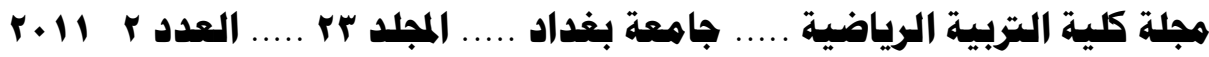

كلها بشكل نسق واحد من خلال الحاسوب التي يمكن من خلالها التعبير عن المعارف

المختلفه باكثر من وسيلة في نظام واحد يتم التخطيط له جيدا(1).

امـا نتـائج المجموعـة الضـابطة التـي اسـتخدمت الوسـائل المعتـادة وإلمعتمـدة بتنفيـ

دروس التربية الرياضية فقد كانت نتائج مستويات التعلم غير دالة بين نتائج القياسين القبلي والبعدي.على الرغم من ان هنـاك تطورا في الاوسـاط الحسـابية للاختبارات البعديـة لهذه المجموعة لهذه المهارات نتيجة تعلمهم في دروسهم العملية.

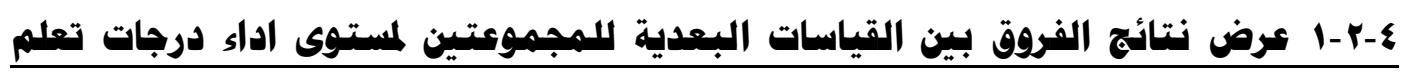

\section{هذارة الوقوف على الراس وتمليلها}

(ب) الجدول (r)

الأوساط الحسابية والانحرافات المعيارية وقيمة (t) المحسوية ودلالة الفروق بين

المجموعتين الضابطة والتجريبية في الاختبار البعدي في مستويات تعلم الاداء لمهارة الوقوف على الراس قيا البحث

\begin{tabular}{|c|c|c|c|c|c|c|c|c|}
\hline \multirow{2}{*}{ الفروق } & \multirow{2}{*}{ مستوى } & \multirow{2}{*}{ المحسوية } & \multicolumn{2}{|c|}{ مج الضابطة } & \multicolumn{2}{|c|}{ مج التجريبية } & \multirow{2}{*}{ المتغير ات } & \multirow{2}{*}{ المهارة } \\
\hline & & & $\varepsilon^{ \pm}$ & سن & $\varepsilon^{ \pm}$ & سن س & & \\
\hline دال & $\because$ HY & ץ.779 & 1.0 r & $r . r \cdot r$ &. .799 & ะ.V V V & الأراعان (د) & \multirow{5}{*}{ الوقوف على } \\
\hline دال & .019 & 1. & I.VYA & rד &. rVo & $V_{.} \odot V_{0}$ & الرجلان (د) & \\
\hline دال & $\because \cdots$ & $7.11 \leq$ & $1 . r 7 V$ & $r . r \wedge 0$ & $1 . \leqslant V$. & V.Irr & الجذع (د) & \\
\hline دال & $\because \cdots$ & $\Lambda .0 \vee 9$ & $1 . \leqslant \leq \leqslant$ & r.oor & .711 & 7.19 & الرأس (د) & \\
\hline 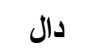 & $\because r \Lambda$ & $\varepsilon .14$ & 1.101 & $r . v \otimes \Lambda$ & $1 .+1 \varepsilon$ & 1.19 & الحركة كاملة (د) & \\
\hline
\end{tabular}

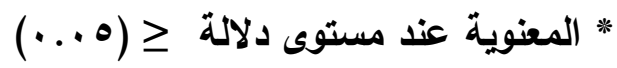

(1) محمد سعد زغلول، واخرون:تكنولوجيا التعلبم واساليبها في التريية الرياضية،طا (مركز الكتاب للنشر، القاهرة، ا . ب) 


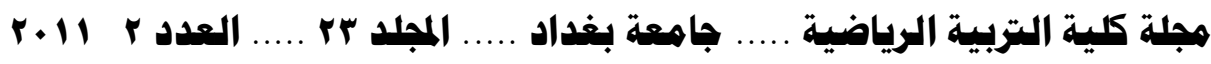

يظهر من نتائج الجدول السـابق ان الوسط الحسـابي البعدي للمجموعـة التجريبيـة لدرجات الاداء لمهارة الوقوف على اليدين ( للذراعين واللرجلين والجذع والـراس والحركـة

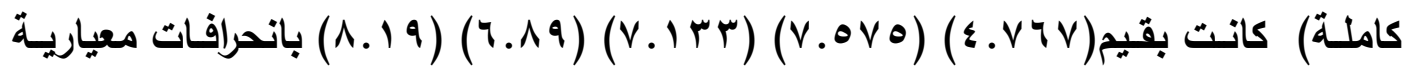

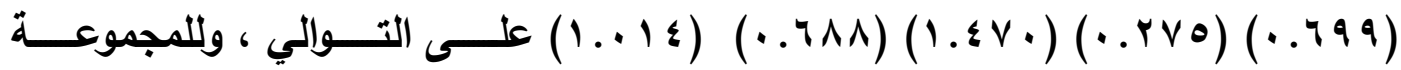

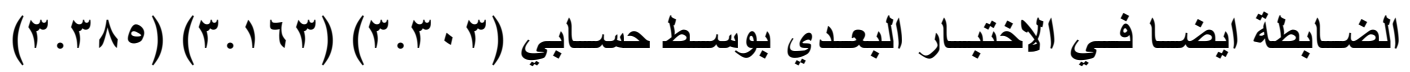

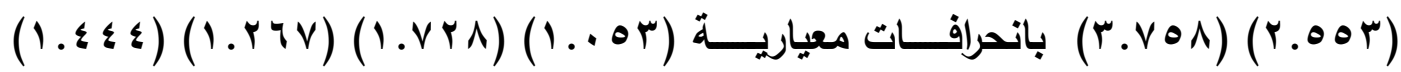

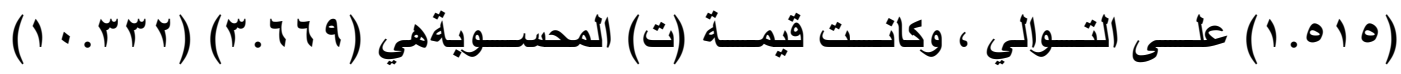

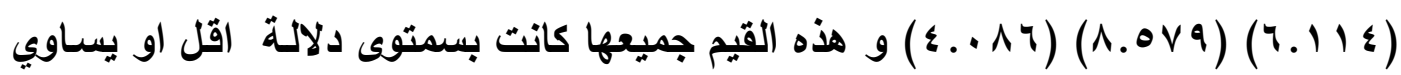
ه . . . . وهــا يـدل علـى وجـود فـروق ذوات دلالـة معنويـة لصـالح الاختبـارات البعديـة للمجموعة التجريبية. يلحظظ تفوق المجموعـة التجريبيـة التـي خضـعت السى برنـامج التـعلم بالحاسـوب والصـورة الثابتة(الوسـائل المتعددة) في تعليم مهارات الجمناسـتك على نتائج المجموعـة الضـابطة ، اذ كانـت الفـروق بـين الاوسـاط لمتغيـرات الدراسـة جميعها لصسالح المجموعـة التجريبية.

ويعزو الباحث تفوق المجموعة التجريبية إلى ان هذا الاسلوب زاد من شدة الحوافز لاى الطلاب اثناء التعلم ، الامر الذي جعلهم يؤدون المهارات الخاصـة باتقان عالٍ و بحماس كبير ، إذ يـكر (الطالب والـويس 99 ( ) ) " إن مستوى الانجـاز يتناسـب تناسباً طردياً مـع درجة التحفيز " (1).

(1) نزار الطالب، وكامل الويس : علم النفس الرياضي ، دار الحكمة للطباعة والنثر ، بذاد ، بـ9 (11، 11) $(r \cdot 9)=$ 


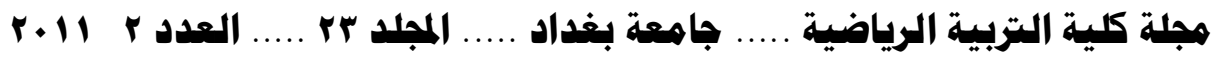

§-צ عرض نتائج الاحتفاظ للمبموعتين وتهليلها ومناقشتها

جدول (צ)

نتائج الاحتفاظ للمجموعتين

\begin{tabular}{|c|c|c|c|c|c|c|}
\hline للفقبة المئوية & نسبي & سَ احتفاظ & سَ بعدي & سَ قبلِي & المجوعة & المهارات \\
\hline \%। צ, &., 79 & $v, 0$ & $\wedge, 19$ & $r, q \leq$ & تجريبية & \multirow{2}{*}{ الوقوف على الراس } \\
\hline$\% \mid r . . r o$ & . . & r.70 & $r . r \cdot r$ & r.VT & ضابطة & \\
\hline
\end{tabular}

يوضـح الجدول (ع) قيم الوسط الحسـابي للاختبـارين القبلـي والبعدي والاحتفـاظ للمجموعة التجريبية لارجة الاداء للحركة كاملة لمهارات الوقوف على الراس إذ بلغت هذه

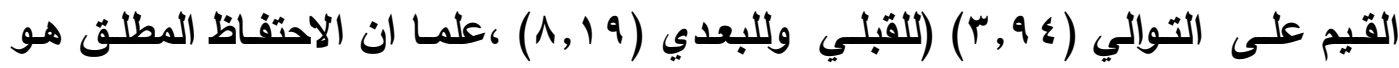
الدرجة التي نراهـا بعد مدة ( الاحتفاظ مباشرة)(') ، امـا النسبة المئويـة للفقدان فقد بلغت

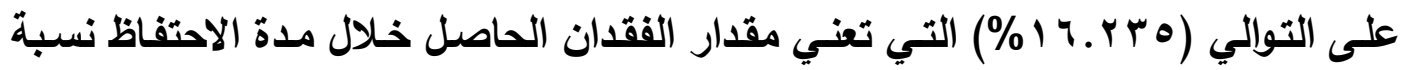
الى مقدار التطور الحاصل في المهارة في مدة التعلم الاولى(التطور الحاصل بين الاختبار

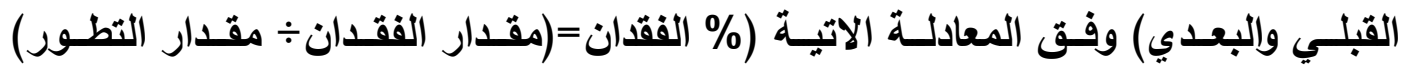
(r) $(1, \times x$ امسا الضابطةيوضـح الجـدول (ع ) قيم الوسـط الحسـابي للاختبـارين القبلـي والبعـدي والاحتفــاظ للمجموعـة الضــابطة لدرجـة الاداع للحركـة كاملـة لمهــارات الوقـوف علـى

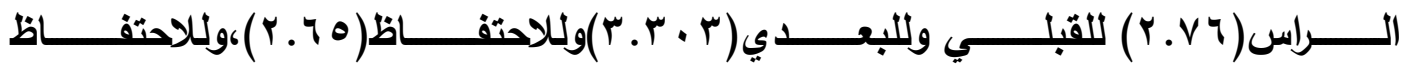

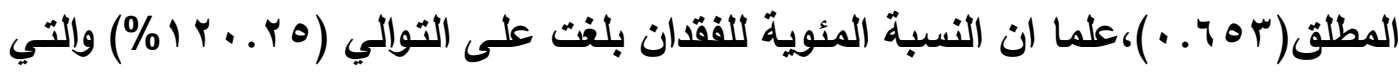
تعني مقدار الفقدان الحاصل خلال مدة الاحتفاظ نسبة الى مقدار التطور.

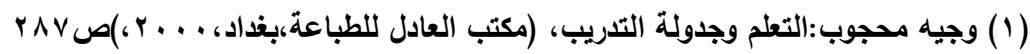

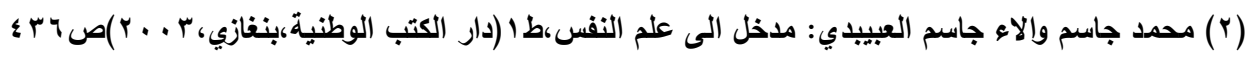




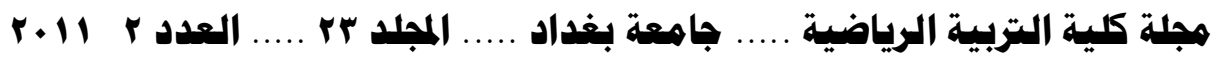

يعزو الباحث تقدم المجموعة التجريبية في مستوى الاحتفـاظ للمهارات قيد الدراسـة الحى البرنامـج التعليمي الذي سمح للمتعلم بالتحكم في سرعة المعلومـات وتتابعها التي يحتاجها

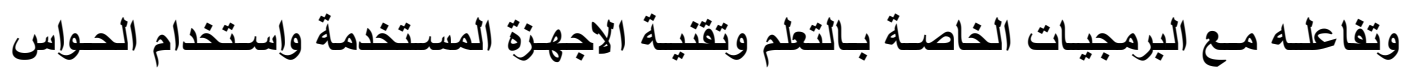
بالتعلم مما سمح بالتفاعل المتناسق لاكبر عدد من وسـائط التعلم والاتصـال والحاسوب، و كما هو معروف انه كلما زاد عدد الحواس المشتركة في التعلم زاد مقدار الاحتفاظ له

\section{البـباب الخاهـس}

0- الاستنتاجات والتوصيات 0-1 الاستنتاجات

1 ـ اسهمت الوسـائل التعليمية المتقدمة في تطور حركات الذراعين والرجلين والراس والجذع لمهارات الجمناستك والسلة للمجموعة التجريية بشكل واضح. ץ. نتيجة البرنامـج التعليمي ظهر تكامل الاداء الصركي لمجمل المهارة المطلوبـة الذي تمثل بتطور الارجة النهائية للاداء. للمجموعة التجريبية. ب. لـم يكن التطور ملموسـا في مستويات الاداء الحركي لحركات الرجلين والذـراعين والرراس والجذع لمهارات الجمناسـتك لدى افراد المجموعة الضـابطة التي تعرضت للاروس المعتادة اليومية او الاسبوعية. ع. ان عرض المهارات قيـ الدراسـة بواسطة الحاسـوب اعطى مـردودات ايجابيةة في المي تسهيل عملية التعلم من خلال مـا يشاهده الطالب من دقة العرض للمهارات فضـلاً عن قابلية العرض البطئ مما وفَّر فرصـة جيدة في معرفة دقائق الحركات وسرعة

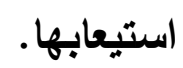




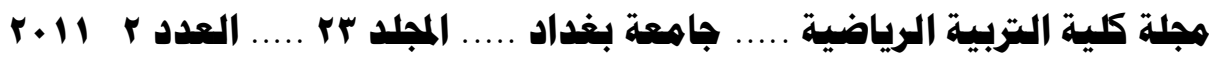

r r-o

ا ـ ضـرورة إدخـال المـدارس كافة التقتيـة الحديثة إلـى مناهجها وخططهـا التعليميـة

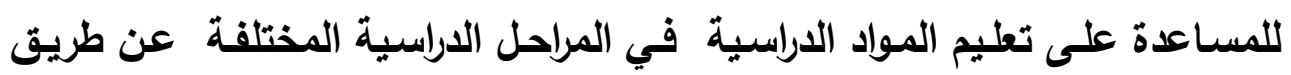
توظيف التقنية في خدمة التعليم؛ بهدف تأهيل خريجيها إلى التفاعل مـع المحيط بكفاية وفاعلية ولمواجهة تحديات التعليم. r. ضرورة ان تعمل وزارة التربية في العراق، على تطبيق منظومات التعليم بالحاسبة الاليكترونية في مدارسها. وعلى مختلف المراحل.

ب. توضيح المفـاهيم المغلوطة عن تكنولوجيـا التعليم والخلط بينها ويـين تكنولوجيـا المعلومات والاتصالات التي تعد من أدواتها ، فضلاً عن إلى فصل مفهوم التعليم

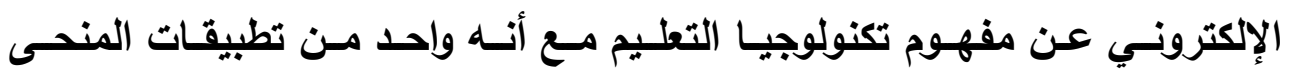
التكنولـوجي في المنـاهج الدراسـية لترسـيخ اسـتخدام تقتيـات التتعلم والتعليم في المدارس.

ع. إن تعميث أثر العملية التريويـة التعليمية ونجاحها يحتاج إلى تنمية قدرات المعلم ومهاراته لكي بحسن انتقاء وإستخدام الوسيلة التعليمية التي تمده بآليات تساعده على تقديم المادة وتوجيها الى المتعلم في سـاحة الدرس العملي. ويذلك لا تحدث الفجوة بين المادة النظرية وإلمستقبل، وهذا لا يتحقق إلا إذا أقيمت دورات تدريبية للمعلم حتى تنمو لايه ملكة إنتاج الوسيلة التعليمية واستخدامها. 


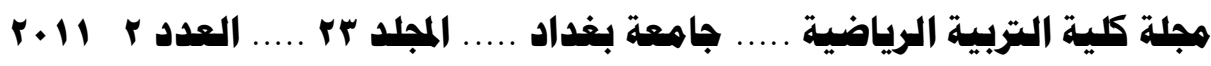

\section{المسادر العربيسة والأجنبيسيسة}

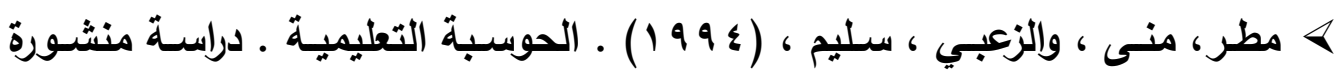
حول إدخال الحاسوب للمدارس القلسطينية ، مركز عبد الرحمن زعرب .

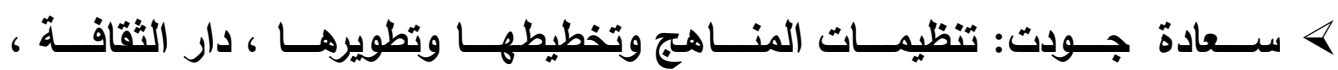

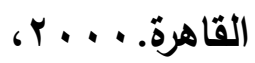

\& مصطفى جويفل واخرون : نموذج مقترح لتوظيف منظومات التعليم الإكترونـي في

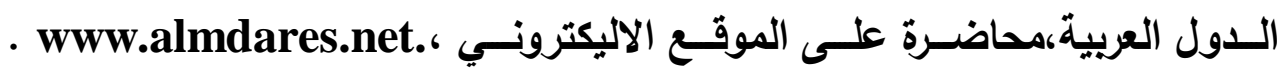
تكنولوجيا التعلم. ه التحليل النوعي في علم الحركة، (ترجمة صريح عبد الكريم ووهبي علوان) الدار

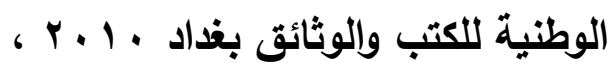

ه محمـ جاســم ، والاء جاسـم العبيــي : مـدخل الــى علـم الـنفس ، ( دار الكتب

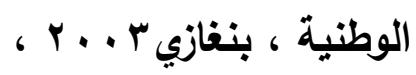

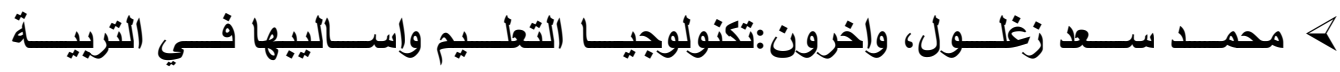

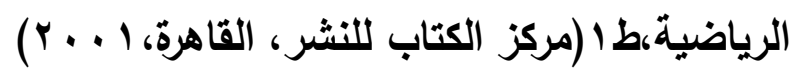
ه نزار الطالب، وكامل الويس : علم النفس الرياضي ، دار الحكمـة للطباعة والنشر ، بغداد ، بr (6)

>

$>$ Jwaifell, Mustafa. (2007). "E-Learning Objects Me style Enabled Educational class, Enhancing Blended learning" LINC Conference, Amman, Dubai. 